\title{
URBANIZAÇÃO E REPRESSÃO AO COMPORTAMENTO NEGRO EM SALVADOR NO SÉCULO XIX
}

\author{
Nilene Matos Trigueiro Marinho iD1 e Ricardo Figueiredo Lucena (D)2
}

\section{Resumo}

Com o desenvolvimento das urbes e as leis de abolição no século XIX, o negro ganha as cidades brasileiras ocupando-se dos trabalhos referentes à infraestrutura urbana, assim como do trabalho doméstico. A exposição, cada vez maior, de suas manifestações culturais em vias públicas provocaria a perseguição do Estado e da elite branca, que argumentava a ausência de códigos de conduta e civilidade no comportamento destes indivíduos. A partir destas questões, pretendemos analisar a condição do negro na cidade de Salvador no século XIX, momento em que um processo de urbanização mais intenso desenvolve-se e, com ele, um discurso em torno de comportamentos e códigos sociais de conduta e civilidade. Para cumprir os intentos do estudo fizemos uso da pesquisa bibliográfico-documental, com inserção em alguns periódicos da Hemeroteca Digital da Biblioteca Nacional, que tratavam da presença negra nas cidades no século XIX. A leitura de Elias se fez de grande relevância na compreensão dos conceitos de civilização, de conduta, de regras de etiqueta, marcadamente utilizados nos textos dos periódicos para justificar a necessidade de expurgar os negros e suas manifestações dos espaços públicos das cidades. Procuramos entender o comportamento da elite branca brasileira estabelecida em relação aos negros e acreditamos que a relação entre os dois grupos esteve inserida em uma figuração estabelecidos/outsiders, no interior de um esforço civilizador, na capital baiana.

Palavras-chave: Negros; Urbanização; Repressão.

\section{URBANIZATION AND REPRESSION OF BLACK BEHAVIOR IN SALVADOR IN THE 19th CENTURY}

\section{Abstract}

With the developement of cities and the abolition laws in the 19th century, the black wins the Brazilian cities dealing with both urban infrastructure and domestic work. The increasing exposition of its cultural manifestation on public roads would provoke the persecution of the State and of the white elite, who argued the absence of codes of conduct and civility in the behavior of these individuals. From these questions, we intend to analyze the condition of the black

${ }^{1}$ Doutora em educação pela Universidade Federal da Paraíba; professora do curso de licenciatura em Educação Física do Instituto Federal do Ceará, campus Juazeiro do Norte.

²Doutor em Educação Física e professor do curso de pós-graduação em educação da Universidade Federal da Paraíba. (c) (i) $($ ) 
in Salvador city in the 19th century, time when a more intense urbanization process develops and, with it, a speech around behaviors and social codes of conduct and civility. In order to fulfill the study's purpose we made use of bibliographic and documentary research, with insertion in some journals of the digital hemerotheque of the national library, which dealt with the black presence in the cities in the 19th century. The reading of Elias was of great relevance in understanding the concepts of civilization, of conduct, of behaviors, markedly used in texts of periodicals to justify the need to purge blacks and their manifestations from the public spaces of cities. We seek to understand the behavior of the established white Brazilian elite towards blacks and we believe that the relationship between the two groups was part of established/ outsiders figuration, within civilizing effort in capital of Bahia.

Keywords: Blacks; Urbanization; Repression.

\section{Introdução}

A chegada da família real ao Brasil, em 1808, impulsionaria a formação do Estado Nacional, inaugurando uma nova etapa no desenvolvimento da nação. Conforme Lucena (2001, p. 15), "[...] essa situação produziu, com a introdução de um conforto e luxo ainda desconhecidos na colônia, uma transformação dos hábitos e abriu caminho para as grandes mudanças que a cidade e, por conseguinte, o País, passou a sentir a partir de então".

Mudanças físicas, econômicas e culturais, o aumento populacional, o intenso convívio nas relações sociais e de trabalho, entre outros fenômenos, provocaram novas relações e inter-relações inauguradas, diante de uma crescente interação e dependência estabelecidas na complexidade das interdependências.

As modificações nas relações de trabalho, cada vez mais presentes em sociedades urbanizadas, exigiam uma série de diferenciações e de atitudes capazes de impulsionar o processo de individualização em andamento que, por sua vez, possibilitou uma melhor compreensão dos laços de interdependência e da forma como estes são capazes de unir, separar e hierarquizar indivíduos e grupos sociais.

À medida que a diferenciação funcional torna as pessoas mais interdependentes entre si, ela as deixa mais dependentes do centro, no que concerne à integração e à coordenação (ELIAS, 2012). Aqueles que exercem funções centrais nestas sociedades disporão de maiores possibilidades de poder.

E ainda que a concentração de poder estivesse, nas metrópoles brasileiras, nas mãos da elite branca, elas não conseguiram sustentar os fenômenos que possibilitaram o surgimento de novas vinculações e inter-relações, que, por sua vez, eram inauguradas diante de uma crescente interação e dependência dos primeiros com as classes menos favorecidas, entre elas, os negros que ganhavam as ruas das cidades. 
As mudanças em curso no país sucederam a partir de uma continuidade histórica sobre a camada dos impulsos emocionais, em curto prazo, e sobre os impulsos superegoicos em longo prazo. As tensões não emergiram sem forças propulsoras elementares, como a luta pela sobrevivência do negro, tampouco sem forças de longo prazo, como o desejo da elite branca de manter a propriedade, a segurança, a proteção social elevada, a conferir-lhe poder sobre os demais. Esta forma sublimada de desejo, que satisfaz o ego e o superego, expressou-se através da monopolização dos bens por um pequeno grupo economicamente abastado e de pele clara, ao lado da monopolização da fome elementar sofrida por um grande número de pessoas, a maioria negra. Estas situações cresceram em importância para a gênese das tensões sociais, na mesma medida em que as funções sociais, psíquicas e o padrão de vida normal avançam para além das necessidades imediatas.

A coação realizada no campo pelos senhores e feitores transmutava-se nas urbes para o controle dos gestos, comportamentos e emoções dos sujeitos cativos e negros livres, assim como, da população em geral, que se submetia às normas, leis e posturas. Estas evocam um maior controle sobre o corpo, enfatizando o desenvolvimento de uma nova situação emotiva no Brasil do século XIX, que surgia ao lado de um discurso construído acerca do desenvolvimento de um esforço civilizador no país.

Os códigos de postura eram uma composição metódica e articulada de disposições legais e regras autorizadas pelos legisladores para designar a convivência em sociedade. No Brasil, eles estão presentes desde o Período Colonial, época em que a elaboração, a aplicação e a punição ficavam a cargo das Câmaras Municipais. Neste contexto, a metrópole fazia uso destes dispositivos para impor sua autoridade e zelar pelos bons costumes nas colônias.

Em Salvador, não foi diferente. Os códigos estavam presentes desde o Período Colonial. A priori, eram compostos por um corpo reduzido e simples de normas regulatórias e de convivência, que, ao longo do tempo, foram ampliados com o crescimento e o desenvolvimento da cidade e seu código político, obrigando a população soteropolitana ao cumprimento de deveres de ordem pública (SÁ, 2010).

Intensificou-se também, em Salvador, durante o século XIX, a tentativa de manter o controle emocional da população negra. Para isso, o Estado fundava-se na perseguição às suas manifestações culturais, acusando-as de serem incivilizadas, por não se alinharem aos gestos e comportamentos adotados pelas práticas de origem europeia, percebidas como modelos de educação e civilidade.

É a partir desta cidade, localizada no estado da Bahia e habitada por diferentes grupos, que nos dispomos a analisar, sob as lentes de Elias, como se configurou a repressão ao comportamento negro, alvo de perseguição sob a batuta do Estado, responsável por desenvolver mecanismos capazes de controlar o corpo, as emoções e os costumes desta população que ganhava, cada vez mais, as ruas. 
Elias (1992), em seus escritos acerca da sociedade ocidental moderna, demonstra que não existe atitude natural no homem, mas, sim, um processo de condicionamento e de adestramento. Seus escritos nos permitem compreender como, no curso das transformações sociais ocorridas em longos períodos de tempo e em determinada direção, a afetividade e o controle do comportamento humano individual, por limitações internas e externas, bem como a estrutura de todas as formas de expressão foram alterados, em uma direção particular (ELIAS, 2011).

Suas reflexões acerca das relações entre estabelecidos e outsiders também auxiliam, descortinando conceitos que explicam os conflitos presentes nas relações étnico-raciais para além dos centrados na cor da pele. Elas denunciam a afinidade entre o julgamento moral, contido nos boatos dos estabelecidos e algumas teorias sociológicas que disseminam e inferiorizam os outsiders, bem como a presença de agentes sociais como jornalistas, elaboradores e implementadores de políticas, que contribuem para a naturalização das diferenças e das formas de percebê-las.

Elementos como a percepção de superioridade social e moral, a autopercepção, o reconhecimento, o pertencimento e a exclusão também perpassam pela dimensão da vida social e pelas relações de poder presentes em grupos imensamente desiguais, como negros escravizados e a elite branca.

Independente da posição social ou da condição financeira, os brancos carregavam consigo, em países como o Brasil, a concepção de superioridade étnica para justificar seu status elevado. As condições de pobreza e de baixo padrão aquisitivo a que foram submetidos os grupos negros e a consequente e concomitante humilhação foram utilizadas como justificativa. Do outro lado, persistia um sentimento de inferioridade humana gerado entre os membros do grupo pela elite branca, em meio à relação conflituosa que se estabeleceu.

Seguindo a teoria eliasiana, acreditamos que mudanças na estrutura das emoções e do controle humanos, a exemplo das posturas municipais criadas na cidade de Salvador, durante o século XIX, são fruto de modificações na sociedade e na estrutura das personalidades, tendendo, cada vez mais, a uma direção particular e a um nível mais alto de diferenciação e de integração social.

Situamo-nos um pouco antes da abolição da escravatura, ocorrida em 1888, quando metrópoles como Salvador puderam vislumbrar relações entre indivíduos de diferentes grupos étnicos e origens sociais. Não obstante, aqui nos interessa conversar sobre as relações estabelecidas entre negros, sejam eles cativos e/ou libertos e brancos pertencentes às classes favorecidas que conviviam desenvolvendo figurações sociais, que se apresentavam, em alguns momentos, bastante conflituosas e, em outros, mais brandas.

Neste tipo de relação denominada de étnico-racial, mesmo que a aparência física e a cor da pele sejam marcas distintivas utilizadas para estigmatizar o outro, o aspecto saliente ainda é o fato de grupos estarem unidos de modo que um deles possui recursos de poder mais elevado, barrando o acesso do outro grupo ao poder e ao contato mais estreito, até mesmo com seus próprios 
membros, relegando-os à posição de outsiders (ELIAS; SCOTSON 2000). Neste tipo de ligação, a forma de vinculação sobressai a qualquer característica apresentada por eles. O medo de contaminação, a raiva e a repulsa que um indivíduo do grupo estabelecido apresenta em relação a um sujeito outsider "[...] não difere nos casos em que os indivíduos são distintos em sua aparência física e naqueles que são fisicamente indistinguíveis, a ponto de os párias menos dotados de poder serem obrigados a usar uma insígnia que mostre sua identidade" (ELIAS; SCOTSON, 2000, p. 32).

Para descortinar as questões pertinentes à análise, tomamos o caminho da pesquisa bibliográfico-documental, cujas fontes utilizadas foram jornais da Hemeroteca Digital, da Biblioteca Nacional, que demonstraram serem ricos na construção do resgate histórico do objeto.

Os próximos tópicos abordam, num primeiro momento, de forma breve, o lugar ocupado pelo negro no processo de urbanização da cidade de Salvador, ocorrida no século XIX e, num segundo momento, a tentativa incessante dos brancos estabelecidos e do governo desta cidade de controlar os corpos, destruir costumes e cercear as emoções dos negros que ganhavam as ruas da cidade.

\section{O negro em Salvador}

Salvador teve, durante muitos anos, a função de sentinela do litoral brasileiro, de sede administrativa e de elemento polarizador da vida na colônia, de porto e mercado de exportação. A cidade foi a expressão econômica da Bahia, nos primeiros anos do século XIX. Por seu porto, escoava a produção agrícola e comercial do Recôncavo.

A partir do século XVI, a sociedade baiana estabeleceu vínculos muito fortes com a escravidão. Até meados do século XIX, a venda de cativos também estava na pauta comercial. Em Salvador, funcionava o maior mercado de escravizados do nordeste (BIASIN, 2011).

As primeiras leis de alforria impactaram a cidade, provocando sentimentos contraditórios, como o medo dos grupos dominantes da massa escravizada que ganharia as ruas. O medo é um dos responsáveis por impulsionar a força dos superegos e instilar uma autocompulsão na forma de vergonha e no senso de honra, garantindo o controle das pulsões (ELIAS, 1993).

Em cenários como este, os indivíduos tendem a canalizar as suas pulsões e emoções, bem como seus comportamentos, através de um controle imposto de uns sobre os outros, enquanto as limitações são atribuídas à pessoa a quem são impostos medos de outros tipos. A constante reprodução de medos é inevitável e indispensável onde quer que o ser humano viva, onde quer que os desejos e atos dos indivíduos se influenciem mutuamente, seja no trabalho, no ócio e no amor. Tais medos não estão fundados apenas nas necessidades básicas da coexistência humana, como também não se vinculam simplesmente a questões, como um equilíbrio estável entre os desejos de muitos e a manutenção da cooperação social, os códigos de conduta e a vida em sociedade. As restrições a que os indivíduos são submetidos e seus medos correspondentes são 
determinados por forças específicas, geradas pela sociedade, pelo seu poder, outros diferenciais e as tensões que criam (ELIAS, 1993). Em contextos como estes há, segundo Elias (1993, p. 255),

[...] aumento - sob pressão da integração social corporificada na intensidade da concorrência dentro da própria classe alta e na necessidade de preservar seu alto padrão de vida e prestígio sob os estratos mais baixos - de um tipo de controle social específico, de sensibilidade ao comportamento de outros membros da própria classe, de autocontrole individual e de força do "superego" individual.

O medo das classes estabelecidas intensificou-se em Salvador, durante o século XIX, por fatores como a abolição e, a consequente invasão de uma grande quantidade de sujeitos vindos do interior, que migraram em busca de melhores condições de vida, já que o subemprego aumentava e não existiam indústrias capazes de absorver a mão de obra rural.

Fatores como estes impeliram um maior contato e intensificaram a tensão entre as classes proprietárias e os grupos marginais, sentido, também, nas práticas culturais entre os séculos XIX e XX.

Até meados do século XIX, a venda de negros também estava na pauta comercial de Salvador. A partir do século XVI, a sociedade baiana estabeleceu vínculos muito fortes com a escravidão. Em Salvador, funcionava o maior mercado de escravizados do norte. Os negros eram rapidamente expostos nos comércios para serem vendidos ou alugados. Estas cenas deixavam muitos estrangeiros perplexos (BIASIN, 2011).

A capital baiana era uma metrópole comercial-escravista no século XIX, que explorava a mão de obra negra de forma intensa. Neste mesmo período, esta mão de obra ganhava as ruas, sendo todos os serviços urbanos realizados por cativos ${ }^{3}$. Consoante Viana Filho (2008, p. 173),

[...] as menores cousas, os trabalhos mais insignificantes, tudo era realizado pelo negro. Nos sobrados, nos engenhos, nos campos, toda atividade seria absorvida pela massa escrava, importada da África, e cuja inteligência facilmente aprendia os cuidados necessários ao serviço para que era designada. [...] Tendo como intermediário o feitor, o senhor do engenho mandava, gritando e repreendendo das largas varandas dos sobrados, onde uma multidão de negras e molecotas se atulhava, cozinhando, fazendo doces, cosendo, varrendo, criando meninos, catando "cafuné" na cabeça dos amos. Os senhores do engenho amoleciam preguiçosamente, enquanto o negro trabalhava. Eram homens,

\footnotetext{
${ }^{3}$ A escravidão humana era dividida em três grandes grupos, no que se refere aos postos de trabalho: escravos de ganho, escravo de aluguel e escravos domésticos. Essa compartimentação não era bem definida, visto que o escravo poderia transitar facilmente nos diversos tipos de serviço. Dessas três modalidades, apenas os escravos de ganho podiam apropriar-se de alguma renda, fruto de seu trabalho, geralmente desenvolvido em atividades como: transporte de pessoas, de mercadorias, de lenha e o comércio ambulante de diversos produtos como doces, frutas, etc.
} 
dizia-se na época, "que não sabem pôr o pé no chão e que não podem deixar de empoleirar-se numa cadeirinha e que até para conduzirem uma folha de papel lhes he mister um escravo"

O transporte de pessoas, com as cadeirinhas, concentrava o maior número de trabalhadores escravizados. "[...] As cadeirinhas de arruar eram o principal meio de transporte usado em Salvador, constituindo um elemento marcante na paisagem urbana, sempre descrita pelos viajantes estrangeiros, e encontradas nos 'cantos' à disposição dos fregueses [...]" (COSTA, 1991, p. 22).

Mesmo depois do surgimento dos primeiros veículos tracionados por animais, no século XIX, Salvador não conseguiu extinguir as cadeirinhas de arruar transportadas por negros. Ainda, neste mesmo século, surgiram os primeiros automóveis como destacou, o jornal Gazeta de Notícias ao chamar atenção para a necessidade de adaptar a estrutura urbana às novas necessidades decorrentes da crescente demanda de automóveis em Salvador, visto que "novos ou velhos, e estes mais do que outros, estão, de passo a passo, no conserto. Nenhum escapa a essa fatalidade, a que condenam como uma ruína infallivel, os máos caminhos da cidade [...]" (GAZETA DE NOTÍCIAS, 1912, p. 1) A Gazeta de Notícias atribui as mudanças nas ruas à chegada da vida civilizada e esclarece que,

[...] dia a dia vem crescendo o número de "autos". E todos trabalham. Sinal de que a vida civilizada, de agitação, de movimento, está, o que é verdade, aumentando entre nós. Somente esses velozes carros não dispõem de estradas para o seu andar alegre. Mexem-se com dificuldades pelas ruas estreitas e os calçamentos, máos, aos boléus, desengonçando-se a cada momento, e, de tanto topar, contam as horas de proveito pelas de desmancho - nas madeiras e nas machinas, nas rodas, nas borrachas, na direção, em tudo.

Os pobres não tinham acesso a nenhum tipo de veículo e se locomoviam a pé; todavia, os indivíduos pertencentes à elite continuaram a utilizar as cadeiras de arruar, que eram mais baratas do que os novos veículos de locomoção e já haviam se transformado num hábito arraigado na sociedade.

Conforme o Relatório dos Trabalhos do Conselho Interino de Governo da Bahia (1853, p. 66), havia a necessidade de utilizar esta massa escravizada no uso das cadeiras de arruar, devido à falta de investimentos que as tornavam a única opção de transporte de pessoas, como destacado abaixo:

[...] As cadeiras são, em geral, mais necessidade do que luxo pela situação da capital; e não se podendo esperar nem que esse trabalho seja procurado por pessoas livres, nem que tão cedo se adopte um outro meio de condução, o resultado he que esta se torna mais custosa servindo até os impostos de pretexto para desarrazoadas exigências [...]. 
As mudanças vão ocorrer com o abandono do uso do africano que, a priori, preenchia a lacuna responsável pela ausência de estrutura das cidades, exercendo desde o transporte de pessoas e mercadorias ao abastecimento de água, escoamento de dejetos, abastecimento alimentar, limpeza urbana, iluminação, funcionamento interno das habitações etc. (GOMES, 1990). De acordo com Pinheiro (2011, p. 96),

[...] o africano chega ao Brasil, inicialmente, para trabalhar nas plantações de cana-de-açúcar, como opção econômica para o incremento da agricultura de exportação. Com o crescimento urbano, o trabalho dos negros volta-se para os serviços na cidade, em todos os setores da vida da urbe, seja nas ruas ou nas casas, utilizado tanto para permitir luxos da vida civilizada - como lacaios, por exemplo -, quanto para executar os mais vis serviços - como jogar as imundícies no mar ou nas lagoas.

A cidade crescia e, com ela, o número de cativos que passaram a ocupála, marcando uma territorialidade negra que se espalhava das freguesias aos largos, ladeiras e praças. No interior deste contexto, perpetuava-se a estigmatização e a exclusão dos negros pela elite branca, que fundamenta seu poder na exclusão de pessoas da condição de humanidade plena. Os outsiders seriam menos humanos, num sistema social extremamente desigual, mantido por crenças infundadas.

Em Salvador, a freguesia da Conceição abrigava a maior parte do comércio, com armazéns que realizavam vendas em grosso, pequenas lojas e o comércio de rua (COSTA, 1991). O porto localizado nesta freguesia, com seu intenso movimento, também demandava o serviço de transporte.

Assim, como o restante do país, a capital baiana viu-se dividida, ao final do século XIX, entre os costumes do Império com seus valores monárquicos e o desejo de transformação, que trazia consigo a modernidade, representante do novo século e da República.

A urbanização também trouxe consigo a redução do poder do senhor e a ampliação do controle do Estado. Foram criadas posturas e decretos para controlar a mobilidade, o corpo e o comportamento dos outsiders que lá habitavam e trabalhavam.

A atribuição de características como ruim ou pior aos negros foi outra distorção que facultou ao grupo branco provar suas qualidades, sendo os fatos sempre construídos na direção de provar a superioridade do seu grupo.

A marginalização do povo africano foi forjada na construção da identidade do colonizador, que se constituiu em oposição às características do grupo escravizado. Foi através da negação do povo dominado, possuidor de características "não pertencentes" ao homem branco que o colonizador normalizou a escravidão, tornando-a "invisível". Esse processo acontece porque a construção da identidade é marcada pela diferença, e esta "[...] pode ser construída negativamente - por meio da exclusão, da marginalização daquelas pessoas que são definidas como outros, ou forasteiros" (SILVA; WOODWARD; 
HALL, 2014, p. 50). Esse cenário observa-se na descrição de Chiavenato (2012, p. 150) sobre a escravidão, que

[...] legitimou sua existência usando os preconceitos nascidos do trabalho escravo como fundamentos ideológicos que reduziam o negro a "ser inferior", garantindo o "direito ético" das classes dominantes de usá-lo sem considerar sua condição humana. O negro era a besta de trabalho: não se questionou ou sequer se pensou a sua humanidade. O processo começou antes do primeiro africano chegar ao Brasil, teve sutis formas de sedimentação e arraigou-se a tal ponto na sociedade escravista que os preconceitos passaram a história e prevalecem ainda hoje, mais de cem anos depois da abolição.

Diante deste contexto de exclusão, a autonomia conquistada nos "cantos" pode ser entendida como uma pequena parcela de liberdade no interior do sistema escravista e, também, como constituinte de um espaço cultural próprio, resistente às adversidades.

Os trabalhadores negros do sexo masculino, fossem eles livres ou não, exerciam como principal atividade, em Salvador, o serviço de transporte de pessoas e o ofertavam em locais de grande circulação, como a Rua Nova do Comércio, a Rua das Princesas; em largos, onde havia pontos de convergência, como o largo de Guadalupe, um dos pontos de articulação da Freguesia da Sé; e nas ladeiras, como a do Taboão, ponto de ligação da cidade alta com a cidade baixa. Na Praça da Piedade, local de grande circulação de pessoas e onde havia um chafariz, que era utilizado por negros aguadeiros (COSTA, 1991).

Negros livres e escravizados, bem como a elite branca, na Salvador do século XIX, estavam inseridos numa larga e diferenciada rede de interdependências. A posição de ambos os grupos no interior destas cadeias requereu-Ihes maior contenção dos impulsos momentâneos e pulsões, refletidos em seus comportamentos e gestos. Nesse sentido, O Nothiciador Catholico (1855, p. 467) afirmou:

Si no $\square 15$ da citada pastoral de 4 de Novembro de 1814 o sábio Prelado extranhou com indignação o abuso que fazem de muitas pessoas dos Presepios que armam em comemoração do nascimento do nosso Senhor Jesus Christo com muita maior razão se deve clamar e prohibir a falsa devoção com que muita gente festeja a S. Antonio por esses mattos com batuques, danças, cantigas e todas as indecências que depõe contra nossos costumes; e altamente injuriam ca Deos e a seos Santos; e querendo tirar tão grande abuso ordeno ao Rev. Parocho que instrua a seus Fregueses na verdadeira devoção e no cazo de contumácia, sejam privados dos Sacramento todos aquelles que concorrerem diretamente a esses festins.

Os comportamentos ditos civilizados pautavam-se nos modos europeus, que surgiam arraigados numa expressão de autoconsciência utilizada, 
especialmente, pelos grupos dominantes do Ocidente. As modificações ocorridas nos padrões de comportamento e em sua estrutura civilizadora como um todo estiveram intimamente relacionados ao desenvolvimento urbano destes países.

Apesar de uma maior proximidade física e social entre os sujeitos, possibilitada pelas cidades e da redução dos diferenciais de poder intergrupos, os conceitos vinculados aos sentimentos e percepções intergrupais que desconsideravam e inferiorizavam o negro não desapareceram, deste modo, sua cultura, religiosidade e conhecimentos continuaram sendo atacados. $E$ no decorrer do século XIX e início do século $X X$, sofreram um processo de branqueamento e maior aceitação social.

Cabe destacar que as mudanças nos gostos e costumes e, principalmente, nos "estilos" que sucederam no Brasil a partir do século XIX, não foi do dia para a noite, mas foram fruto de um processo lento, num período de tempo considerável. Elas não ocorreram como construção de um único indivíduo, mas tiveram por base transformações nas relações de poder entre grupos distintos, entre eles, os negros escravos e cativos e a elite branca.

Para ordenar a presença negra de trabalhadores nas ruas da capital baiana e regulamentar seus serviços e espaços, foi promulgado o Regulamento, de 14 de abril de 1836, que tratava da "formatação da capatazia de ganhadores" (COSTA, 1991).

Caberia aos Juízes de Paz de cada freguesia estabelecer os locais específicos para as capatazias e nomear inspetores que fariam a matrícula dos ganhadores, a qual conteria o nome do ganhador, o de seu senhor, caso fosse escravo, o local de moradia e o serviço a que se destinava. Dentre as atribuições dos inspetores estava a de vigiar a conduta dos indivíduos, ou seja, exercer o controle do funcionamento de cada canto (COSTA, 1991, p. 26).

Os negros que residiam nas cidades possuíam funções no comércio e na prestação de serviços, em que podiam negociar o valor de seu trabalho com o cliente e entregar, periodicamente, uma quantia predeterminada ao seu senhor.

A vida do negro de ganho era menos vigiada do que a do africano que trabalhava na zona rural, onde se observavam diretamente os trabalhos, tendo em vista a proximidade das moradias dos negros com a casa-grande. Na zona rural, era comum que os escravizados residissem próximos à casa de seus senhores. Os senhores que dispunham de mais posses construíam senzalas, a grande maioria, sem o mínimo de conforto ou estrutura capaz de acolher a vida humana. Nestas, os cativos dormiam junto aos animais e seus excrementos.

Em Salvador, os negros que trabalhavam nas urbes podiam residir fora das casas de seus senhores. As moradias eram barracos, cortiços, lojas ${ }^{4}$ e porões

\footnotetext{
4"[...] Eram assim denominados os espaços situados em térreos e subsolos das edificações plurifamiliares, ou mesmo, os espaços de moradia nos porões das casas tipologicamente conhecidas como 'de porão alto'. [...]. Através de anúncios, em jornais de meados do século XIX, sobre venda ou aluguel de imóveis em Salvador, podemos identificar a tipologia interna dos casarões coloniais, na qual se evidencia a sua subdivisão em várias unidades, e a presença das 'lojas de aluguel'" (COSTA, 1991, p. 29).
} 
(GOMES, 1990). As condições de higiene dessas habitações "eram bastante precárias, caracterizando-se pela excessiva umidade, ventilação deficiente e ausência quase total da luz solar. Muitas destas habitações formavam verdadeiros cortiços" (COSTA, 1991, p. 31).

O centro de Salvador passou a ser ocupado por estas moradias, que, além de negros, a maioria alforriados, eram habitadas por imigrantes pobres. Os indesejados sociais, "[...] aos poucos, começaram a afugentar os vizinhos com melhores condições econômicas, especialmente, para a Vitória, uma elegante periferia ao sul da cidade, que passou a ser mais habitada a partir de 1850 " (BIASIN, 2011, p. 37).

Tais habitações, duramente perseguidas pelo governo como sinônimo de imundície, delinquência e vícios, não raras vezes, foram removidas dos centros da cidade. Segundo Costa (1991), apresentavam as seguintes características:

[...] em áreas periféricas, as chamadas roças, que aos poucos vão sendo incorporadas ao tecido urbano, como também e sobretudo, se reapropriando de áreas pré-existentes. As habitações são variadas, seguindo as características de moradia dos pobres: sublocavam quartos nas casas dos libertos, que eram geralmente construções modestas, de taipa, térreas, de porta e janela; alugavam quartos em vilas de aluguel (avenidas), nos fundos de quintais; ou choupanas de taipa cobertas com palha, como também habitavam nas chamadas "lojas" (COSTA, 1991, p. 29).

A perseguição às moradias recriava um discurso estigmatizante, comumente atribuído aos outsiders, neste tipo de relação, que os afasta do convívio social seriamente comprometido pela comparação que os reduz e destina-Ihes adjetivos como sujos, de cheiro desagradável e desprovidos de qualidades humanas (ELIAS; SCOTSON, 2000).

$\mathrm{Na}$ zona rural, era comum que os cativos fossem alocados próximos à casa de seus senhores. Em Salvador, a senzala estava fortemente presente na zona rural, representando "[...] o espaço de confinamento de uma mão de obra utilizada intensivamente sob o controle do senhor e de seus pressupostos, cujos olhos vigilantes estão sempre presentes [...]" (GOMES, 1990, p. 10).

A coação existente no campo, realizada pelos senhores e feitores, transmutava-se na cidade na forma de controle dos gestos, dos comportamentos e das emoções, com base nas normas, leis e posturas, sob o controle estatal. Essas normas e posturas evocam um maior controle sobre o corpo, enfatizando o desenvolvimento de uma nova situação emotiva no Brasil.

Os impulsos mais comedidos estavam sob um olhar menos vigilante do que na reclusão das senzalas, sob o chicote do feitor; por isso, eram mais livres de determinadas amarras. Pode-se dizer que a cidade representou para estes indivíduos um espaço de manifestação, "[...] onde é possível ser sozinho e compor, no grupo, um tema comum" (LUCENA, 2001, p. 34). 
No que se refere às posturas municipais, pode-se dizer que denotam uma tentativa do Estado de arrogar para si o direito do uso da força sobre os indivíduos. No entanto, a escravidão era um empecilho para a monopolização do uso da força, visto que ainda existia um forte grau de dependência e de subordinação pessoais, necessárias à sustentação do regime escravista. Conforme (DECCA, 2001, p. 4),

[...] a subordinação do escravo exigia a manutenção de um aparelho de força nas mãos dos senhores e uma vasta camada social de dependentes e responsáveis pela manutenção do sistema. Neste sentido, podemos perceber de que maneira os séculos de escravidão comprometeram a formação de uma verdadeira esfera pública no Brasil. Também podemos entender como as elites letradas brasileiras, nem sempre sensíveis aos ideais humanitários, procuraram introduzir hábitos e valores europeus que pudessem minimizar para si mesmas as imagens negativas da sociedade escravagista colonial.

Na sociedade escravista, a exemplo de Salvador, o homem branco participava do controle do monopólio estatal da violência física. Já os negros, conforme o artigo 179 da Constituição brasileira de 1824, eram percebidos como uma propriedade plena, coisa desumanizada. Este dispositivo constitucional destinava aos primeiros a possibilidade de tomar decisões sobre a vida e a morte dos segundos e aprofundava drasticamente a distância social entre os grupos, que não dispunham de nenhuma igualdade simbólica.

No entanto, mudanças estavam a caminho. A cidade crescia e alterava a estrutura das personalidades rumo a uma diferenciação de controles emocionais e na estrutura social como um todo, com vistas a um nível mais alto de integração, que visava a um prolongamento das cadeias de interdependência e a consolidação de controles estatais. É sobre questões como estas, presentes na cidade de Salvador do século XIX, que o próximo tópico se debruça.

\section{A perseguição às práticas negras na cidade de Salvador}

Temendo revoltas, badernas e roubos, o poder público esforçava-se para tentar coibir a circulação dos negros nas ruas de Salvador, conforme aponta a postura existente na capital baiana, que proibia a "[...] permanência de escravos em estabelecimentos comerciais por mais tempo que o necessário ou ainda aquela que obrigava o escravo a trazer consigo, após às 21 horas, uma espécie de 'salvo conduto' [...]"' (GOMES, 1990).

O medo das classes proprietárias tornou-se uma poderosa força motriz de controle social entre seus membros. Medo que foi expresso não só na vigilância de comportamentos com que observavam e puniam as pessoas de classe mais baixa, a exemplo das posturas municipais e dos sinais de status, mas também nas falas, gestos, boas maneiras e distrações (ELIAS, 1993). Nesse contexto, é relevante destacar a matéria do jornal 0 Constitucional, que chama atenção do relato de um de seus assinantes acerca da prática de batuques em Salvador. 
[...] Parece que a polícia dorme o sono da indolência, sem que sinta ou seja informada para o que se passa na rua das cajazeiras há muitos dias, na qual, em certos casebres, reunindo-se pessoas da mais baixa esfera da sociedade contra o que está prescrito no Regimento no 120 de 31 de janeiro de 1842, incomodam a vizinhança com batuques e ofendem a decência e a amoral pública com a dança denominada - o quebra caroço - Nem sequer essa gente respeitou os dias quarta e quinta-feira santa". "Por essa mesma ocasião pede a polícia, querendo examinar a boa gente que durante a noite se reúne no canto denominado do Cotó -, donde por vezes hão partido insultos a pacíficos viandantes, donde hão saído cacetes para se quebrarem cabeças $[\ldots]$ (O CONSTITUCIONAL, 1863).

Intensifica-se, no século XIX, a pressão sobre comportamentos e práticas culturais dos indivíduos pobres e negros, considerados repugnantes. A partir de então, instalou-se no Brasil uma constante preocupação com os costumes de um modo geral. Criam-se as posturas municipais como integrantes de um processo de individualização, que é reconhecido pelo indivíduo, num primeiro momento, como um mecanismo de controle imposto pelo Estado, mas que, a longo prazo, será internalizado. Estes, por sua vez, têm seus impulsos mais controlados e aprendem a desenvolver relações mais íntimas, particulares e nãopúblicas.

Mesmo diante das perseguições, as cidades ampliavam as possibilidades de os negros desenvolverem novos laços de relacionamento, bem como, suas tradições culturais e religiosas. Ainda que diminuídas e violentadas, suas manifestações conseguiram sobreviver de maneira sincrética às perseguições e carregar em seu interior, o caráter de luta e resistência. De acordo com Santos (2009, p. 54),

[...] as práticas culturais e religiosas afrobrasileiras preservavam e reconfiguravam saberes de matriz africana, ao tempo em que ajudavam os seus participantes na elaboração de balizas de outras identidades que reinterpretavam heranças africanas na diáspora, insubordinando-se, muitas vezes, contra discriminações de classe, raça e de caráter religioso.

As manifestações culturais, realizadas nas ruas e perseguidas pelo Estado, cumpriam, entre os cativos, a função de congregar e de partilhar. Elas eram reconhecidas popularmente como batuques e envolviam uma série de manifestações que iam desde a religião, à prática de atividades corporais como a capoeira, que os uniam e fortaleciam, dando-lhes poder e, mesmo que por curtos momentos, possibilitavam-lhes ascender na sua condição de cativos. A coragem ganhava corpo, fazendo-os enfrentar situações que, sozinhos, seriam impossíveis. 
Em alguns momentos, o que era denominado pelos jornais como baderna representava a necessidade de integração entre indivíduos que disfrutavam da mesma condição social e tinham uma semelhança em relação à cultura.

Os escravos representavam uma ameaça à ordem estabelecida e provocavam medo nas autoridades competentes e na elite. Esse sentimento era nutrido por diversas rebeliões negras, a exemplo da revolta dos Malês ${ }^{5}$, sucedida em 1832. "[...] A cidade vivia, portanto, num estado de permanente tensão, daí ser preciso todo um aparato legal de controle dessa massa escrava" (COSTA, 1991, p. 21).

A educação do corpo imposta ao negro, por meio de violência física e cultural, tornou-se um mecanismo bastante útil no controle dos negros que passaram a ocupar os espaços urbanos. Ao tomar uma proporção maior do que a desejada pela elite, a saída foi investir em discursos que, acompanhados do uso da força e do extermínio dos corpos africanos, exaltavam a necessidade do citadino desenvolver comportamentos diferenciados. De acordo com Santos (2009, p. 46),

[...] No Brasil, sobretudo a partir da Independência, setores da elite dispensaram progressiva atenção à temática da "civilização". Esta era representada como uma conquista progressiva e cumulativa, todavia, necessitava de luta contra a tradição, a superstição e o instinto irracional. Dessa maneira, o assim chamado "paganismo africano", em suas manifestações privadas ou públicas, mereceu acalorados discursos e práticas que os repreendia. $\mathrm{Na}$ base do paradoxo "tolerar ou reprimir" presente nas estratégias de setores da elite para civilizar os costumes dessas terras, encontrava-se uma forte perspectiva de controle dos negros escravizados, ou seja, era a manutenção da ordem que estava no núcleo dos dois paradigmas de tratamento da festa negra.

O repúdio às práticas negras, nas cidades, tornou-se evidente na declaração realizada pelo jornal O Farol Paulistano, em 1829, lembrado como um instrumento de mobilização e debate político, o jornal publica uma carta, na sessão "Correspondência", de um sujeito que se apresenta sob a alcunha de "Um Estudante" e desfere críticas a um professor de francês. As críticas giram em torno do comportamento reprovável dele, que incluí o jogo de capoeira em espaços públicos da Bahia e de São Paulo. Segundo "Um Estudante", ao ser inquirido sob a insatisfação do público em suas aulas, o professor de francês rebateu as críticas afirmando agradar às autoridades e ao público. No entanto, o autor do artigo não concorda e afirma ter havido evasão nas aulas do respectivo docente, motivadas pelo seu estranho comportamento. Como declarado no jornal:

\footnotetext{
${ }^{5}$ Malês, termo utilizado pelos baianos para tratar os nagôs e hauçás. Foram os mais letrados africanos a aportar em terras brasileiras e mantinham contato com a África. Os primeiros hauçás chegaram em 1607 e tinham uma religião fundada em um sistema de cultura, em que era necessário saber ler e escrever. Não era incomum encontrar hauçás mais cultos do que os seus senhores. Os malês chegados à Bahia, em 1805, já possuíam experiência nas jihads africanas. Ambos os grupos eram formados por vários sacerdotes e militares em suas terras de origem (CHIAVENATO, 2012).
} 
[...] andar pelas ruas suspendendo pernas de cavalos para serem ferrados e jogar capoeira no Largo do Chafariz, o logar mais público, e frequentado dessa cidade, servindo de espetáculo aos negros, que quando o vêem dar bem uma cabeçada, o aplaudem com bastante assobios, palmas e gargalhadas? Custa a crer senhor redator; porém é verdade. Eis aqui qual é, e tem sido a boa conduta do mestre de francez, o seu bom ensino, a satisfação das Auctoridades, o que espera delle o Público. Queira pois, Sr. Redator, por esta última vez inserir em sua Folha esta correspondencia, afim de que os Brazileiros, que não conhecem o mestre de Francez, e nem estão ao fato do seu procedimento, saibão agora quem foi ele na Bahia, e quem é em São Paulo (O FAROL PAULISTANO, 1829, p. 1048).

A elite e a imprensa da época pregavam o fim das manifestações culturais de origem afro-brasileira, incentivando a substituição destas pelas práticas europeias como o carnaval que, ao modelo francês, deveria substituir o entrudo $^{6}$. Este atrai a desconfiança de setores da sociedade e ganha a censura do poder público, que lhe imputa a alcunha de manifestação primitiva que atenta contra o bom gosto, a moralidade e a saúde (LUCENA, 2001).

No entanto, o sincretismo tomou conta das festas populares e o modelo de carnaval apregoado pela elite foi ressignificado pela população, aproximandose das manifestações afro-brasileiras.

Não foram poucas as tentativas de exclusão social e cultural dos negros nas urbes brasileiras, elas iam desde a criminalização de suas práticas até o controle da mobilidade desses indivíduos, os quais assistiram e contribuíram, diretamente, para o surgimento das cidades, lutando para criar mecanismos de inclusão.

A exclusão dos negros não se deve as diferenças raciais ou étnicas em si, mas ao fato de um dos grupos ser estabelecido, dotado de recursos superiores, e o outro ser outsider, inferior em relação ao referencial de poder e contra o qual os estabelecidos podem cerrar fileiras (ELIAS; SCOTSON, 2000). "As figurações estabelecidos-outsiders possuem regularidades e divergências recorrentes. [...] No fundo sempre se trata do fato de que um grupo exclui outro das chances de poder e de status, conseguindo monopolizar essas chances. A exclusão pode variar em modo e grau, pode ser total ou parcial, mais forte ou mais fraca" (ELIAS; SCOTSON, 2000, p. 208).

Quase todos os grupos humanos tendem a perceber outros grupos como pessoas de menor valor do que eles mesmos. O grau de estigmatização pode variar de ruidoso e bárbaro, como na estigmatização dos africanos no Brasil, ou

${ }^{6} \mathrm{O}$ entrudo era um jogo de origem portuguesa, assim classificado por Lucena (2001, p. 38): "[...] Um instante onde homens e mulheres, crianças e velhos, negros e brancos ganhavam o espaço público e faziam das bacias d'água e dos limões de cera, para uns, e dos pós e papas, para outros, um jogo que quebrando a casca da cera, trazia para dentro da folia até aqueles que estavam apenas de passagem". 
ter uma tonalidade mais amena. Consoante Elias e Scotson (2000, p. 201) "[...] Não só pequenas comunidades, mas também homens e mulheres, governos e partidos políticos, assim como dúzias de grupos que costumamos caracterizar por sua proveniência "étnica", estão entrelaçados em muitas sociedades como estabelecidos e outsiders".

A estigmatização surge como um dos aspectos da relação estabelecidos/outsiders e associa-se, não raras vezes, a uma fantasia criada pelo grupo estabelecido que reflete e justifica o preconceito de seus membros pelos outsiders. O estigma social que os primeiros atribuem aos segundos transformase, em sua imaginação, em estigma material e é coisificado, surgindo como algo objetivo implantado pela natureza ou pelos deuses. Assim, o grupo estabelecido redime-se de qualquer responsabilidade, ao atribuir a algo além de suas vontades e comportamentos a situação vivida pelos estigmatizados.

Neste cenário, a referência à cor da pele e outras características inatas e biológicas dos grupos tratados como inferiores assume uma função objetificadora. O sinal físico torna-se o símbolo tangível de pretensa anomia do outro grupo, do seu valor humano inferior, de sua maldade intrínseca e oculta a defesa da distribuição e da oportunidade de poder vigente e sua função exculpatória (ELIAS; SCOTSON, 2000).

A exclusão do negro ocorria também por meio da segregação espacial e desinteresse do poder público sobre as áreas em que habitavam. Constituíramse políticas de desafricanização dos espaços públicos, de europeização das cidades e de imigração, as quais se fundamentavam em um modelo de civilização universal, desconsiderando os conflitos existentes, bem como, as diferenças econômicas, políticas, sociais e raciais (CUNHA JÚNIOR, 2007).

Ao final do século XIX, o cenário da escravidão começa a sofrer alterações com a Lei Eusébio de Queiroz promulgada em 04 de setembro de 1850, a Lei do Ventre Livre de 1871, a Lei dos Sexagenários de 1885, que tratavam, respectivamente, da proibição do tráfico de negros da África para o Brasil; da liberdade dos filhos de mulher escravizada que nasceram no Império; da liberdade de cativos com mais de 60 anos de idade. Essas leis provocaram um consequente aumento de indivíduos forros nas ruas das cidades que viviam assombradas pelo fantasma da escravidão.

A redução no número de cativos força os produtores rurais a complementar o trabalho escravo com o trabalho livre, de prestação de serviços, pagando a esses últimos o jornal pelo dia de trabalho.

As leis de alforria e a presença cada vez maior de negros forros, ofertando os seus serviços e negociando a sua força de trabalho parece ter impulsionado, nesse período, um deslocamento maior de sujeitos entre as regiões brasileiras. A mobilidade acontecia entre ricos e pobres, por isso deve ser analisada para além da questão econômica, podendo ser considerada, também, como uma forma de criar laços e como um recurso à liberdade (MATTOS, 2013).

Apesar da maior "mistura" entre os diferentes grupos, característica marcante das cidades, o preconceito persistia e os negros viram suas práticas 
veementemente perseguidas nas metrópoles brasileiras e resistiram por meio do sincretismo e da dissimulação que carregavam o caráter de luta, revolta e sobrevivência.

Cabe refletirmos sobre o impacto das fantasias coletivas relacionadas com o desenvolvimento de grupos, criadas para inferiorizar. No caso específico, a fantasia coletiva atribuída ao negro de modo depreciativo lhe destinava características animalescas e selvagens de um ser sem alma e, tinha, neste momento, um papel nas relações de poder que estavam sendo construídas entre os grupos. Havia o receio do negro transitar nas ruas, de estabelecer vínculos com a sociedade e tornar-se, paulatinamente mais, presente na luta por um espaço de trabalho, por sua liberdade e por fazer valer os seus direitos. E é justamente nestes cabos-de-guerra silenciosos, em um contexto de desigualdades, que residem as lutas pelos diferenciais de poder e as desigualdades que lhes são concomitantes (ELIAS; SCOTSON, 2000).

As fantasias que reduziam o negro a um ser selvagem eram utilizadas para embasar a repressão em cidades como Salvador, durante o século XIX, e diante das revoltas negras a repressão assumiu um caráter militar, ganhando contornos de regras de etiqueta e comportamentos destinados ao homem de cor no usufruto dos espaços públicos, dos quais já haviam se tornado conhecidos frequentadores. Como destacou, em 1841, o jornal Correio Mercantil sobre as manifestações negras nas ruas de Salvador:

[...] refletindo, porém, nas seenas que toda essa cidade nos domingos e dias santos, e muito principalmente nas que tiveram lugar, durante oito dias de festejos da coroação, fallemos claro e a vista dos tumultuosos e numerosos batuques dos africanos que por ahi encontra a cada canto o pacífico habitante, e que, horrorizado, fazem no apressar o passo a ganhar a casa; quem não justificará, até certo ponto, esse terror súbito que se apodera de uma população inteira, a semelhante ideia, quando aliás, ainda tem presente a audácia com que em 1833 foram surpreendidos os quarteis... \&c. \&c. \&c? E aqui vem muito a pello apresentar uma censura, que foi geralmente feita por quantos assistirão aos festejos da coroação; fallamos dos multiplicados batuques de africanos que em todas as praças e lugares mais públicos, de dia, e às vezes até alta noite, ferião as vistas e as pobres orelhas dos que se disponham a gozar das belas festas [...] (s. p.).

Os comportamentos foram utilizados pelas autoridades como forma de diferenciação entre os cidadãos de bem e marginais reconhecidos como "arruaceiros" e delinquentes. As posturas municipais compuseram os mecanismos de coerção utilizados na contenção dos corpos negros e suas práticas culturais.

A capoeira, uma manifestação de luta e resistência, sofre no interior desse processo de perseguição uma dura vigilância do Estado. Sua efetividade em contendas de rua e seu uso em atividades ilícitas, como a prática de pequenos furtos e badernas, tornaram-na repudiada e temida. 
Em Salvador, a atenção do poder público aos comportamentos e manifestações culturais, realizadas nas ruas, torna-se intensa devido a duas peculiaridades específicas, a primeira delas, 0 fato de a cidade ser sede administrativa da província e núcleo concentrador de atividades comerciais locais e até mesmo internacionais; e a segunda, deveu-se às características étnicas e raciais da capital baiana e a forma como as populações negras se organizavam no mundo do trabalho.

Houve um embate constante entre as autoridades e os negros residentes, em Salvador, durante o século XIX. Todavia, esse enfrentamento ganhou contornos diferenciados após a segunda metade do século. A repressão policial intensa aos poucos dará lugar à disciplina social, com vistas ao desenvolvimento de uma nova urbanidade. Nesse contexto, as práticas culturais negras são perseguidas e reconhecidas como desordeiras e criminosas.

O embate deve ser percebido a partir de perspectivas culturais distintas, de um lado estava o poder público, representante da ordem e responsável por forjar padrões de convivência e relações sociais urbanas após o declínio da escravidão, e, do outro, estavam os negros que marcavam a sua presença nas cidades com formas culturais singulares de ocupar o espaço físico e social.

O culto aos ancestrais presente nas práticas religiosas negras foi intensamente perseguido em um momento em que o comportamento civilizado do europeu buscava banir de seu convívio a representação de morte (SOUZA, 2005). Acresce-se a isso o fato de os batuques possibilitarem o encontro entre os indivíduos da mesma condição social, significando, para as etnias negras, a expressão de sua autoimagem. Nos encontros, emanavam a emoção de pertencer a um grupo e a celebração expressa em ritos, gritos e danças.

Em uma sociedade que valorizava os comportamentos comedidos e a educação dos gestos, os batuques eram ajuntamentos de negros livres ou forros que perturbavam a ordem, incomodando os cidadãos que tentavam banir seus impulsos das hostes públicas. Diante da situação, o controle do Estado foi utilizado "[...] para conter as emoções que eram abertamente experimentadas pelos indivíduos originários de várias etnias africanas, em diferentes momentos da sociedade brasileira, como revelam algumas fontes produzidas durante a segunda metade do século XIX" (SOUZA, 2005, p. 29).

Souza (2005) chama atenção para o papel da religião católica nas práticas discursivas que fundamentaram a escravidão e as restrições ao comportamento negro. A influência foi diretamente exercida nas posturas municipais que buscavam canalizar as emoções para os ritos cristãos, em que o corpo deveria ser punido pelo pecado original e não festejado como acontecia nos batuques. As proibições evidenciavam que "[...] a etiqueta cristã se perpetuava a partir do momento em que se verificava, em tais práticas, a intensificação emocional por meio dos ritmos, canto e dança, o que contrariava um comportamento polido que não permitia os excessos do corpo em detrimento da alma" (SOUZA, 2005, p. 46). 
A igreja católica possuía as suas irmandades negras na Bahia, tais como a confraria de São Benedito e de Nossa Senhora do Rosário, que denotavam características de sincretismo religioso. Tais instituições possuíam duas funções distintas: aproximar os negros dos ritos católicos, sob o olhar vigilante da igreja, ao tempo que os afastavam de frequentar o mesmo espaço físico de seus senhores no momento do culto. Segundo Vianna Filho (2008, p. 195), "[...] depois das missas, dos sermões longos, das procissões faustosas, seguiam-se as diversões públicas, cânticos e danças, onde se expandia a alma negra [...]". "[...] Como vimos, ainda em 1786, pediam os negros das confrarias para, nas ruas da Bahia, dançarem e cantarem na língua de Angola [...]".

Todavia, a concepção da igreja e de seus integrantes parece não ter sido, de tudo, uníssona, conforme aponta A Marmota, periódico baiano de 1849, que denuncia ao subdelegado da Freguesia da Penha, em Salvador, a atitude do padre Joaquim, capelão da igreja do Bonfim, que permitia a manifestação dos batuques em suas terras. A Marmota apela para que o padre não permita "[...] os batuques, e sambas que ultimamente se tem feito na rocinha da sua rezidência com icommodo da vizinhança, a pouco de privar o sono e repouso das famílias, sob pena de ser suspenso da cape'lania: por um anno, e ser preso na torre do Collegio" (A MARMOTA, 1849, p. 1.013).

O negro estava sempre presente nas festas populares, nas diversões dos domingos, com expressões culturais como a capoeira, o samba, o berimbau que [...] de notas uniformes e monótonas, enche tardes inteiras de ócio, agrupando trabalhadores rurais, que espairecem ouvindo o instrumento primitivo. Ao seu som se fazem desafios de capoeira, os contendores envergando uniformes de marinheiro, de calças descidas apenas até ao meio da perna, enquanto os circunstantes acompanham, com palmas, a melodia que se repete (VIANNA FILHO, 2008, p. 196).

As manifestações culturais expressavam a saudade e funcionavam como uma forma de recordação e de vivência simbólica, por isso, no Brasil, onde viviam negros existiam batuques. Todavia, eles tornaram-se mais evidentes enquanto problema social, nas grandes cidades brasileiras, a exemplo do que foi noticiado no jornal Correio Official (1833, p. 510), da cidade do Rio de Janeiro, o qual apresenta, no extrato das partes da semana, a seguinte questão: "Pelo primeiro juiz de paz da freguesia do sacramento, foram presos, Viríssimo Antônio Português, por suspeito, Ricardo cativo do Doutor Francez Senechal, por desordem, Francisco Antônio, por capoeira; cinco escravos por infração de posturas $[\ldots]^{\prime \prime}$.

Em Salvador, o questionamento de um leitor, que assina como "O contramestre", o jornal O Descobridor de Verdades, de 1822, demonstra a aversão de alguns setores às práticas afro-brasileiras em Salvador:

Dous grupos de negros e negras debaixo dos arcos de Santa Bárbara, fazendo com seus batuques um barulho insuportável, e muito admirei que, sendo o juiz de paz de Freguesia da Conceição da Praia tão severo, para outras cousas, fosse tão benigno em consentir esta, que incommoda a todos. Espera pela resposta para 
tirar-se da incerteza. O sujeito recebe como resposta do redator do jornal: "Não temos presentes as Posturas da Câmara Municipal desta cidade, afirmamos-lhe porém que he voz geral serem prohibidos os batuques de que trata a sua carta. He quanto pode responder-Ihe" (O DESCOBRIDOR DE VERDADES, 1822).

Salvador, em um movimento semelhante ao que vinha acontecendo nas grandes cidades, durante o século XIX, sofreu mudanças responsáveis por incitar a formação de um tecido social mais complexo, gerando um aparato sociogênico de autocontrole individual mais diferenciado e estável. Desenvolveu-se, como consequência destas mudanças um esforço que tinha como objetivo formar o homem "civilizado", que apresentasse um comportamento comedido às ruas e que fizesse uso de seu autocontrole constante e diferenciado.

Como evidenciou as matérias dos jornais, a sociedade soteropolitana passou a punir as explosões e ações emocionais destituídas de um espírito de previsão, principalmente aquelas relacionadas às manifestações afro-brasileiras, tidas como de valor inferior quando comparadas às advindas dos países europeus, que ditavam a moda no século XIX.

\section{Considerações finais}

Salvador viu acontecer, durante o século XIX, uma crescente modificação no comportamento dos indivíduos, fruto da construção de um esforço civilizador no Brasil que ocorria principalmente nas grandes cidades. A construção deste esforço não ocorreu sobremaneira de forma pacífica, ela não se deu de modo harmonioso, como podemos perceber na luta travada pelo Estado e a elite branca para conseguir conter as expressões culturais negras que transbordavam nas cidades, no século XIX. As relações sucediam em meio a tensões e a dependência mútua entre os diversos grupos. A elite branca, por sua vez, encarava a redução de poder e do controle sobre os corpos negros, ocorrido anteriormente com bastante intensidade nas senzalas localizadas na zona rural.

A elite branca exigia das autoridades responsáveis à contenção dos batuques negros em Salvador, no século XIX, e destacava a necessidade da população ter um maior grau de previdência e comedimento em relação às emoções transitórias. Este tipo de comportamento conferia ao grupo branco estabelecido uma vantagem significativa sobre o grupo negro abordado pelos primeiros como inferior, que via suas manifestações culturais serem perseguidas, inclusive, através da criação de legislação específica conhecidas como posturas municipais.

Torna-se mister reconhecer que, a construção de determinados discursos como os que inferiorizavam os negros fazem parte de uma figuração mais ampla. Nesta figuração desenvolveu-se uma constante busca da elite branca soteropolitana por poder e por manter as suas vantagens em relação aos primeiros, tais como: a aceitação social; a exaltação enquanto grupo escolhido detentor das características físicas e sociais mais dignas e nobres; o acesso aos 
diferentes recursos e instituições que a sociedade podia oferecer-lhes, dentre outras.

\section{REFERÊNCIAS}

A MARMOTA. Parte oficial. Edição 254. Bahia, quarta-feira, 4 jul. 1849. Disponível em:

http://memoria.bn.br/DocReader/DocReader.aspx bib $=816485 \&$ PagFis $=53 \& P e$ sq=batuques. Acesso em: 07 maio 2018.

BIASIN, Olívia. Olhares estrangeiros: imprecisões dos viajantes acerca dos oitocentos. In: A larga barra da Bahia: uma província no contexto do mundo. Salvador, EDUFBA, 2011. p. 18 - 55. Disponível em:

http://books.scielo.org/id/wnm5w/pdf/moura-9788523212094-02.pdf. Acesso em 12 mai. 2018.

CHIAVENATO, Júlio José. O negro no Brasil. São Paulo: Cortez editora, 2012.

CORREIO OFICIAL: IN MEDIO POSITA VIRTUS. Ministerio da justiça. Edição no 128, tomo 1., 23 nov. 1833. Disponível em:

http://memoria.bn.br/DocReader/DocReader.aspx bib $=749443 \&$ PagFis $=510 \& P$ esq=capoeira. Acesso em: 28 nov. 1833.

COSTA. Ana de Lourdes Ribeiro da. Espaços negros: "cantos" e "lojas" em Salvador do século XIX. Caderno CRH. Suplemento. p. 18 - 34, 1991. Disponível em: https://repositorio.ufba.br/ri/bitstream/ri/2097/1/CadCRH2007-391.pdf. Acesso em: 09 out. 2017.

CUNHA JÚNIOR, Henrique; RAMOS, Maria Estela Rocha (Org.). Espaço urbano e afrodescendência: estudos da espacialidade negra urbana para o debate das políticas públicas. Fortaleza: Edições UFC, 2007.

DECCA, Edgar Salvadori de. Apresentação. In: LUCENA, Ricardo Figueiredo. 0 esporte na cidade: aspectos do esforço civilizador brasileiro. Campinas, São Paulo: Editora Autores Associados, 2001.

ELIAS, Norbert. A civilização dos pais. Revista sociedade e estado. Vol. 27, n. 13, Brasília, set./dez. 2012. Disponível em: http://www.scielo.br/scielo.php?script=sci_arttext\&pid=S010269922012000300003. Acesso em: 13 dez. 2017.

ELIAS, Norbert. O processo civilizador: uma história dos costumes. Tradução Rui Jugmann; revisão e representação Renato Janine Ribeiro, 2 ed., Rio de Janeiro: Zahar, 2011. 
ELIAS, Norbert; SCOTSON, John L. Os estabelecidos e os outsiders:

sociologia das relações de poder a partir de uma pequena comunidade. Rio de Janeiro: Jorge Zahar Ed., 2000.

ELIAS, Norbert. O processo civilizador: formação do Estado e civilização. Tradução da versão inglesa, Ruy Jugmann; revisão, apresentação e notas, Renato Janine Ribeiro, Rio de Janeiro: Jorge Zahar Ed., 1993, 2 v.

ELIAS, Norbert; DUNNING, Eric. A busca da excitação. Maria Manuela Almeida da Silva (Tradução) Lisboa: Difel, 1992. Disponível em: https://www.academia.edu/4894091/A_busca_da_excita\%C3\%A7\%C3\%A30_ norbert_elias_e_eric_dunning. Acesso em: 10 mar. 2016.

GOMES, Marco Aurélio A. de Filgueiras. Escravismo e cidade: notas sobre a ocupação da periferia de Salvador no século XIX. RUA. Revista de arquitetura e urbanismo. Salvador, v. 3, n.4/5, p. 7-17, 1990. Disponível em: https://repositorio.ufba.br/ri/bitstream/ri/1352/1/3102-7255-1-PB.pdf. Acesso em: 25 mai. 2017.

GAZETA DE NOTÍCIAS. Ano III, Edição no 12, Bahia, 20 set. 1912. Disponível em:

http://memoria.bn.br/DocReader/DocReader.aspx bib $=721026 \&$ PagFis $=89 \& \mathrm{Pe}$ sq=autom\%C3\%B3vel. Acesso em: 08 jun. 2018.

LUCENA, Ricardo de Figueiredo. O esporte na cidade: aspectos do esforço civilizador brasileiro. Campinas, São Paulo: Autores Associados CBCE, 2001.

O CONSTITUCIONAL. O SR. F. P. B. Anno I, Maranhão, 18 abr. 1863.

Disponível em:

http://memoria.bn.br/DocReader/DocReader.aspx?bib=823317\&pesq=negro\& pasta =ano\%20186. Acesso em: 11 mai. 2018.

O DESCOBRIDOR DE VERDADES. Edição n 4, Bahia, 28 ag. 1822. Disponível em:

http://memoria.bn.br/DocReader/DocReader.aspx?bib=749680\&pesq=batuque s\&pasta=ano\%20182 Acesso em: 10 mar. 2017.

O FAROL PAULISTANO (1827 - 1831). Edição no 232, São Paulo, 5 ag. 1829. Disponível em:

http://memoria.bn.br/DocReader/DocReader.aspx?bib=700169\&pesq=capoeir a\&pasta=ano\%20182. Acesso em: 26 jun. 2017.

O NOTICIADOR CATHOLICO (1849 - 1855). Edição n 95, Bahia, 5 mai. 1855. Disponível:

http://memoria.bn.br/DocReader/DocReader.aspx?bib=709786\&pesq=batuque s\&pasta=ano\%20185\&pagfis=2288. Acesso em: 03 jan. 2021. 
MATTOS, Hebe. Das cores do silêncio: os significados da liberdade no Sudeste escravista - Brasil, século XIX. $3^{\circ}$ ed. Revisada, Campinas, São Paulo: Editora da Unicamp, 2013.

PINHEIRO, Eloísa Petti. Europa, França e Bahia: difusão e adaptação de modelos urbanos (Paris, Rio e Salvador) / Eloísa Petti Pinheiro. - 2 ed. Salvador: EDUFBA, 2011. Disponível em:

https://repositorio.ufba.br/ri/handle/ri/5377. Acesso em:

RELATÓRIO DOS TRABALHOS DO CONSELHO INTERINO DE GOVERNO (BA). Edição n 1 , Bahia, 1853, Disponível em:

http://memoria.bn.br/DocReader/DocReader.aspx?bib=130605\&pesq=cadeiras $\% 20$ de\%20arruar\&pasta $=$ ano\%20185\&pagfis=1040. Acesso em: 03 jan. 2021.

SÁ, Tânia Regina Braga Torreão. Códigos de posturas municipais como instrumentos normativos de produção de novas lógicas territoriais: estudo de caso do centro histórico de Salvador. Percurso: sociedade, natureza e cultura. Curitiba, v. 1, no 11, p. 237 - 284, 2010-1. Disponível em: http://revista.unicuritiba.edu.br/index.php/percurso/article/view/309. Acesso em: 12 abr. 2019.

SANTOS, Edmar Ferreira. O poder dos candomblés: perseguição e resistência no recôncavo da Bahia. Salvador: EDUFBA, 2009. Disponível em: http://static.scielo.org/scielobooks/nq/pdf/santos-9788523212100.pdf. Acesso em: 10 fev. 2017.

SILVA, Tomaz Tadeu (Org.); HALL, Stuart; WOODWARD, Kathrys. Identidade e diferença: a perspectiva dos estudos culturais. Petrópolis, Rio de Janeiro: 2014.

SOUZA, Edilson Fernandes de. Entre o fogo e o vento: as práticas de batuque e o controle das emoções. Prefácio à segunda edição Terezinha Petrúcia Nóbrega. Prefácio à primeira edição Lourival Holanda; Recife: Ed. Universitária da UFPE, 2005.

VIANA FILHO. O negro na Bahia: (um ensaio clássico sobre a escravidão). Prefácio a primeira edição Gilberto Freire, notas a terceira ed. Luís Henrique Dias Tavares. $4^{\circ}$ ed., Salvador: EDUFBA, Fundação Gregório de Mattos, 2008.

Recebido em: 12 de março de 2021. Aceito em: 26 de junho de 2021. Publicado em: 30 de junho de 2021. 